\title{
A Comparative Assessment of Patient Safety Culture between Iranian Selected Hospitals and Agency for Healthcare Research and Quality (AHRQ) Report
}

\author{
Mohammad Azmal', Habib Omranikho², Salime Goharinezhad 3 , Rohollah Kalhor ${ }^{4}$, \\ Nayeb Fadaei Dehcheshmeh5, Fereshteh Farzianpour ${ }^{*}$ \\ ${ }^{1}$ Department of Treatment Affairs, Bushehr University of Medical Sciences, Bushehr, Iran \\ ${ }^{2}$ Faculty of Public health, Bushehr University of Medical Sciences, Bushehr, Iran \\ ${ }^{3}$ Health Management and Economics Research Center, Iran University of Medical Sciences, Tehran, Iran \\ ${ }^{4}$ Health Information Management Research Center, Hormozgan University of Medical Sciences, Bandar Abbas, \\ Iran \\ ${ }^{5}$ Health Affairs Department, Ahvaz Jundishapur University of Medical Sciences, Ahvaz, Iran \\ ${ }^{6}$ Department of Health Management and Economics, Faculty of Public Health, Tehran University of Medical \\ Sciences, Tehran, Iran \\ Email: ${ }^{*}$ farzianp@sina.tums.ac.ir
}

Received 26 September 2014; revised 10 November 2014; accepted 19 November 2014

Copyright (C) 2014 by authors and Scientific Research Publishing Inc.

This work is licensed under the Creative Commons Attribution International License (CC BY).

http://creativecommons.org/licenses/by/4.0/

(c) (i) Open Access

\section{Abstract}

Establishing a culture of patient safety can be effective in reducing the incidence of medical errors and solving concerns of safety inadequacy in health systems. The purpose of this study was to assess the culture of patient safety in the selected hospitals, and compare the results with published reports of AHRQ. This study was approved by the Ethical Committee of BPUMS. The subjects signed the informed consent form to participle in the study. Confidentiality was maintained throughout the study reports. Cross-sectional study was conducted in 2012; the study sample was composed of 364 staffs working at two selected hospitals affiliated to Bushehr University of Medical Sciences. Hospital Survey on Patient Safety Culture was used to collect data. Descriptive statistical analysis was used to analyze the data. No reports of events in both studied hospitals and benchmark were accounted for the most of the reported errors, although this indicator in studied hospitals was nearly $23 \%$ higher than that of the benchmark report. The highest patient safety grade in studied hospitals and benchmark was "acceptable" and "very good", respectively. The highest percentage of positive response to patient safety dimension was organization learning and then teamwork

\footnotetext{
${ }^{*}$ Corresponding author.
}

How to cite this paper: Azmal, M., Omranikho, H., Goharinezhad, S., Kalhor, R., Dehcheshmeh, N.F. and Farzianpour, F. (2014) A Comparative Assessment of Patient Safety Culture between Iranian Selected Hospitals and Agency for Healthcare Research and Quality (AHRQ) Report. Health, 6, 3037-3044. http://dx.doi.org/10.4236/health.2014.621342 
within units in studied hospitals. Teamwork within units also was the highest average percent in benchmark report. Non-punitive response to errors had the lowest positive percentage of participant responses in both studies. To achieve the patient safety culture, we do not need to blame individual and apply punitive approach when errors occur. This makes person accept responsibility for their actions honestly and report errors in a timely manner to prevent reoccurrence of similar errors.

\section{Keywords}

Patient Safety Culture, Comparative Assessment, Hospital

\section{Introduction}

Patient safety practices are very important to improve the overall performance and quality of healthcare services [1]. The establishing of a strong patient safety system across a range of groups and technical methods is not clear. In this way, patient safety has attracted a lot of attention from policy makers, practitioners and academics. The policies "to err is human" published by the Institute of Medicine(IOM) in the United States and the "Memory Organization" issued by the Department of Health (DoH), in England, describe how organizational culture can affect staffs attitudes and behavior. Both reports emphasized on the importance of establishing a system which organizational culture can lead to the promotion of safety performance in health care organizations [2].

Organizational culture can be considered as shared beliefs, norms and values of staff in an organization. It is believed that organizational culture can affect the operation and communication patterns [3]. Culture creates a sense of identity and provides a vital link between members and mission of an organization and it is considered as the strongest determinant of the success or failure of an organization. Culture reinforces commitment to organizational goals and directs people to achieve goals by clarifying and strengthening behavioral standards. Safety culture as a subset of organizational culture was mentioned firstly in Chernobyl's report in 1986 [4]. Following the dissemination of this report, the high-risk industries such as aviation and nuclear established the safety culture as a way to reduce occurrence of events [5]. Historically, the industries paid considerable attention to safety assessment and their safety indicators were mostly based on retrospective data about staff's deaths and injuries. It was recently shown that these organizations have considered the organizational, managerial and human factors as the primary cause of events rather simple technical failings and mainly focused on prediction of safety indicators [6]. The healthcare industry is considered as a high-risk industry facing high risk of morbidity and mortality. Patient safety issues have placed into the agenda of assessing institutes of health care facilities such as Institute of Medicine which they recommend that health care organizations must promote a culture of patient safety [7].

Normally when an accident resulting in death occurs in health care centers, activities are just limited to questioning staff by managers and swift forming of patient safety committee [8]. In new paradigm of safety, the focus has shifted from individuals to system, and errors are considered as a defect in the system [9]. And the belief is increasingly growing that the organization's ability to avoid harm is manifested only if the organizations could underpin a safety culture among their staff [10]. A strong safety culture is characterized by: management commitment towards learning from errors, improving patient safety, practicing and encouraging teamwork, identifying potential hazards, establishing reporting system and analysis of adverse events occurring in hospital and finally, assessing patient safety culture among staff [11]. There is always a tension in the areas of patient safety between "no blame" approaches to maintain accountability of providers regarding their practice. After a decade, with emphasis on the approach of "no blame" in response to patient safety risks, the conclusion is that health care providers should be held accountable for their performance [12].

The cultural study of patient safety is a necessity which can provide the feedbacks to the healthcare system to take action improving service quality based on identified problems. Patient safety culture can be analyzed at different levels of the healthcare system and finally through establishment of required structures, major steps towards eliminating weaknesses resulted from thinking, behavioral and professional approach to be taken [13]. This study aimed to examine the outcome indicators of safety culture and their dimensions in selected hospitals in Iran. We also compare the results of this study with AHRQ report to recognize strengths and weaknesses of patient safety culture in these centers. 


\section{Methods}

\subsection{Subjects}

The subjects of the study were 364 clinical staffs from two hospitals affiliated to Bushehr University of Medical Sciences in south of Iran. The hospitals volunteered to establish Patient Safety Friendly Hospital program participated in this study by census sampling. The physician and administrative staffs who did not have direct contact with the patient were excluded. Table 1 shows some characteristics of the studied hospitals.

\subsection{Survey Methods}

A cross-sectional descriptive study was conducted in selected hospital of Bushehr province in summer 2012.

\section{Questionnaires}

There are many tools to assess the patient safety culture/climate. Among them, we used Hospital Survey on Patient Safety Culture (HSOPC), released in November 2004 by Agency for Healthcare Research and Quality (AHRQ) [10]. The survey was designed to assess hospital staff viewpoints on patient safety concerns, medical errors, and error reporting. The survey compromises 42 items that covers 12 composites of patient safety culture as we have shown in Table 2. In addition, the survey also includes two questions about overall grade on patient safety and the number of events reported over the past 12 months in their area/unit.

The validity of this survey has been confirmed in the numerous studies on national and international levels and Cronbach's alpha coefficient as 0.84 .

\subsection{Statistical Analysis}

The questionnaire was distributed among hospital staff. 364 clinical staff (total response rate $41.5 \%$ ) fully completed. SPSS version 16 and descriptive statistics were used for analyzing data. Finally, the results from studied hospitals were compared with data published by AHRQ (2011) with regard to their exiting guideline on [14] [15].

Table 1. Some information about studied hospitals.

\begin{tabular}{|c|c|c|c|c|c|c|c|c|}
\hline Name of hospital & $\begin{array}{c}\text { Foundation } \\
\text { year }\end{array}$ & $\begin{array}{l}\text { Approved } \\
\text { bed }\end{array}$ & $\begin{array}{l}\text { Active } \\
\text { bed }\end{array}$ & Grade & $\begin{array}{l}\text { Clinical } \\
\text { staffs }\end{array}$ & $\begin{array}{l}\text { Administrative } \\
\text { staffs }\end{array}$ & $\begin{array}{l}\text { Total } \\
\text { staffs }\end{array}$ & $\begin{array}{l}\text { Sample } \\
\text { selected }\end{array}$ \\
\hline Fatemeh Zahra & 1966 & 450 & 266 & 1 & 505 & 314 & 819 & 245 \\
\hline 17 Shahrivar & 1985 & 200 & 208 & 1 & 371 & 195 & 566 & 119 \\
\hline
\end{tabular}

Table 2. Characteristics of survey on patient safety culture (HSOPC).

\begin{tabular}{|c|c|c|c|}
\hline No & Composites of patient safety culture & Item & Scale \\
\hline 1 & Communication openness & 3 & 5 points Likert (always to never) \\
\hline 2 & Feedback and communication about error & 3 & 5 points Likert (always to never) \\
\hline 3 & Frequency of events reported & 3 & 5 points Likert (always to never) \\
\hline 4 & Handoffs and transitions & 4 & 5 points Likert (strongly agree to strongly disagree) \\
\hline 5 & Management support for patient safety & 3 & 5 points Likert (strongly agree to strongly disagree) \\
\hline 6 & Nonpunitive response to error & 3 & 5 points Likert (strongly agree to strongly disagree) \\
\hline 7 & Organizational learning—continuous improvement & 3 & 5 points Likert (strongly agree to strongly disagree) \\
\hline 8 & Overall perceptions of patient safety & 4 & 5 points Likert (strongly agree to strongly disagree) \\
\hline 9 & Staffing & 4 & 5 points Likert (strongly agree to strongly disagree) \\
\hline 10 & Supervisor/manager expectations and actions promoting safety & 4 & 5 points Likert (strongly agree to strongly disagree) \\
\hline 11 & Teamwork across units & 4 & 5 points Likert (strongly agree to strongly disagree) \\
\hline 12 & Teamwork within units & 4 & 5 points Likert (strongly agree to strongly disagree) \\
\hline
\end{tabular}




\subsection{Ethical Considerations}

This study was approved by the Ethical Committee of BPUMS. Subjects were explained the nature of the study, and its purposes. The subjects signed the informed consent form to participation in the study. Confidentiality was maintained throughout the study reports.

\section{Results}

A total of 354 staff working in two selected hospitals participated in this study. Table 3 shows the demographic characteristics of the participants. As shown, the majority of participants had between 1 to 5 years' professional experience and worked 40 - 59 hours per week in their current work unit/area. Most respondents had nursing position and had a direct interaction with patients.

Figure 1 demonstrates a comparison between studied hospitals and AHRQ's hospitals on reporting events in the past 12 months.

In both studies the most of respondents had reported no event over the past 12 months, while the proportion at benchmark hospitals is considerably higher (54\% to 30.8\%). With increasing number of reported events are reduced the percentage of respondents reporting events in both reports.

Figure 2 shows Average Percentage of Respondents announced patient safety grade in their work area/units.

According to this chart most respondents in studied hospitals have put patient safety grade in "acceptable level” while highest percentage in benchmark hospitals belonged to "very good" rank. Respondents' attitude on "excellent" grade in benchmark hospitals was significantly higher than studied hospital (29\% to $7 \%$ ). The percentage of positive response of participants to composite of patient safety culture is shown in Figure 3.

In general, the overall average percent positive response to patient safety culture in both studied hospitals and AHRQs' hospitals ware 55.4 and 63.1, respectively. According to Figure 3, the highest percentage of positive responses to the dimensions of patient safety culture belonged to "organizational learning" and "teamwork within units" perspectives in studied hospitals and "teamwork within units" and "supervisor/manager expectation and actions promoting patient safety" in benchmark study. As such, the lowest percentage of positive response was represented by "nonpunitive response to error" items in both studies. "Open communication", "teamwork across units" and "staffing” dimensions in studied hospitals were significantly less than benchmark hospitals.

\section{Discussion}

Based on the study findings, "no event" report had the highest share among the reported events in both studied hospitals and benchmark reports over past 12 months, which is consistent with work of Fajardo-Dolci in Mexico [16] and Baghaei in Iran [17]. Reporting events by health care providers less than real level is generally due to the negative effect of discoursing errors and possible negative reactions received from colleagues, authorities and patients [18]. Establishing an error reporting system along with non-punitive approach can help in reducing current error level and also preventing similar errors happening through considering error an opportunity window for learning and moving towards adopting quality-oriented approaches.

Participants in this study rated patient safety grade "in both hospitals acceptable" and just a small percentage of them have put hospitals in terms of patient safety culture in excellent level. Conversely, in benchmark study, the percentage of respondents that ranked their work area at "excellent" and "very good" was much higher than current study [15]. According to Mikušová work in Croatia 61.9\% of participants rated their hospitals at "excellent/very good", 35\% at "acceptable" and only 4\% at "failing" level [19]. As such, In Abdi's study patient safety grade in two hospitals was at "acceptable" level and one at "poor" on perspective of hospital staff [20]. Generally speaking, creating an effective patient safety culture and implementation of their steps properly can be useful in promoting patient safety in healthcare settings. In this regard, senior managers supporting, participating and supervising the program targeting patient safety would be crucial.

The total average percentage of positive response to patient safety culture was about $55 \%$ and $63 \%$ in studied hospitals and benchmark, respectively. This survey was conducted in the early years of implementing clinical governance program that has considerable focus on patient safety culture. We need sufficient time to establish this culture completely and to achieve the mission considered in its agenda. The reason of slight difference between our findings and AHRQ report probably comes back to short period of establishing patient safety program 
Table 3. Some characteristics of participants.

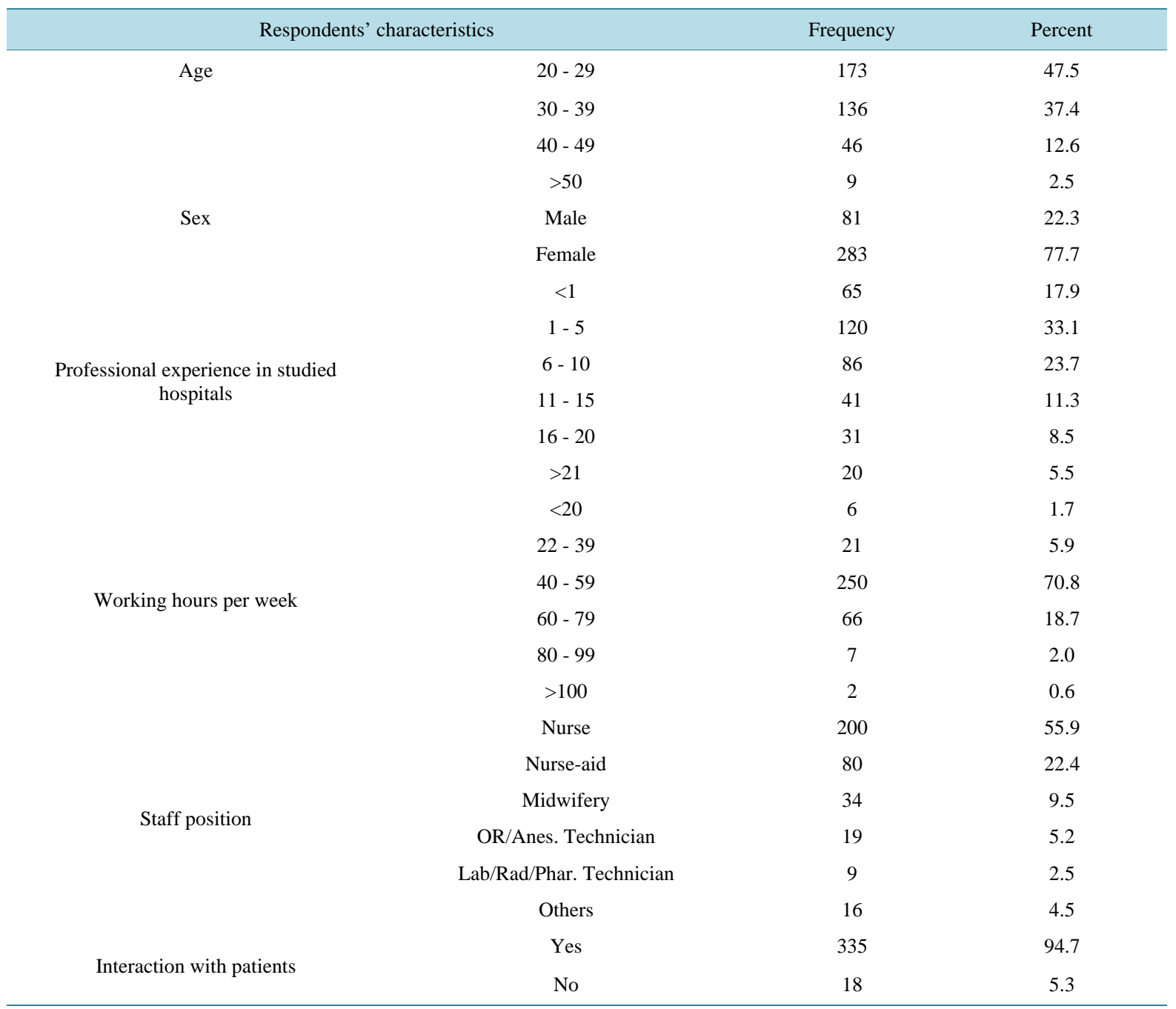

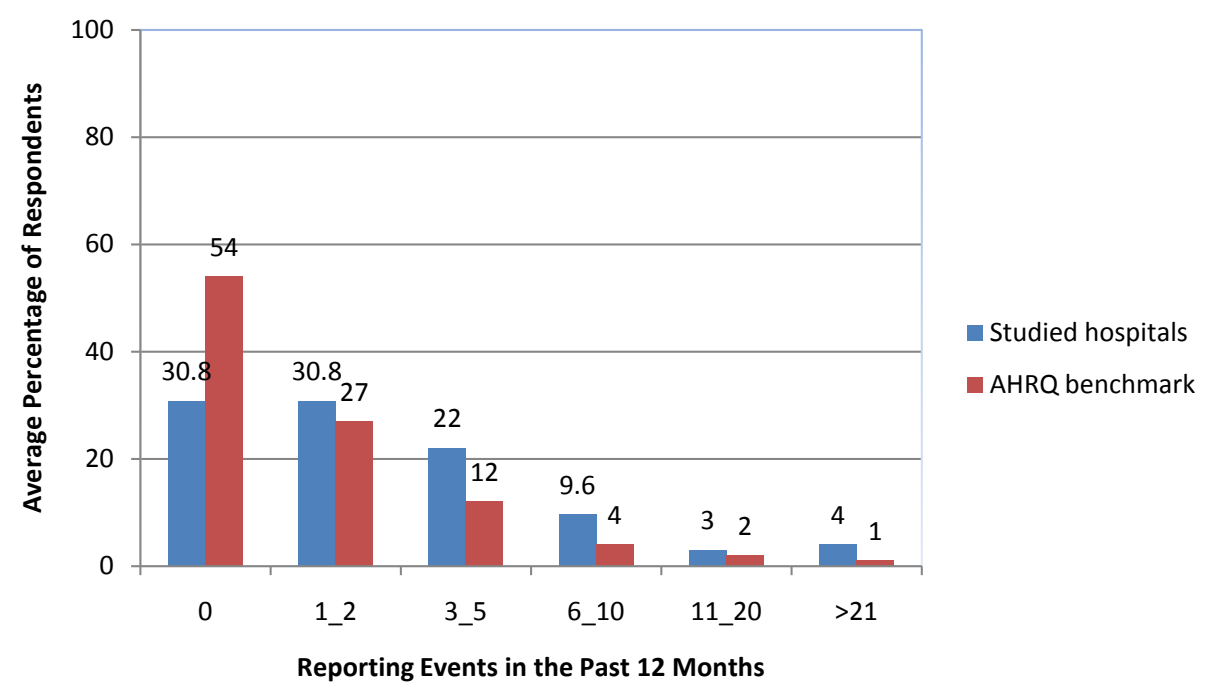

Figure 1. Comparison of average percentage of respondents reported events in the past 12 months between studied hospitals and AHRQ benchmark. 


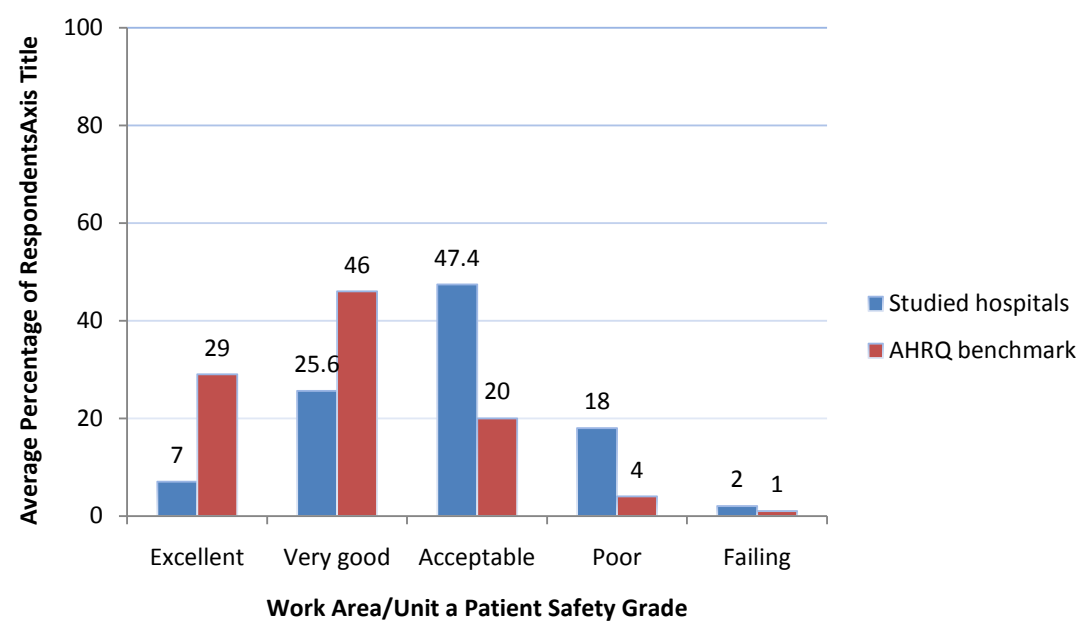

Figure 2. Average percentage of respondents giving their work area/unit a patient safety grade - comparing studied hospitals and AHRQ.

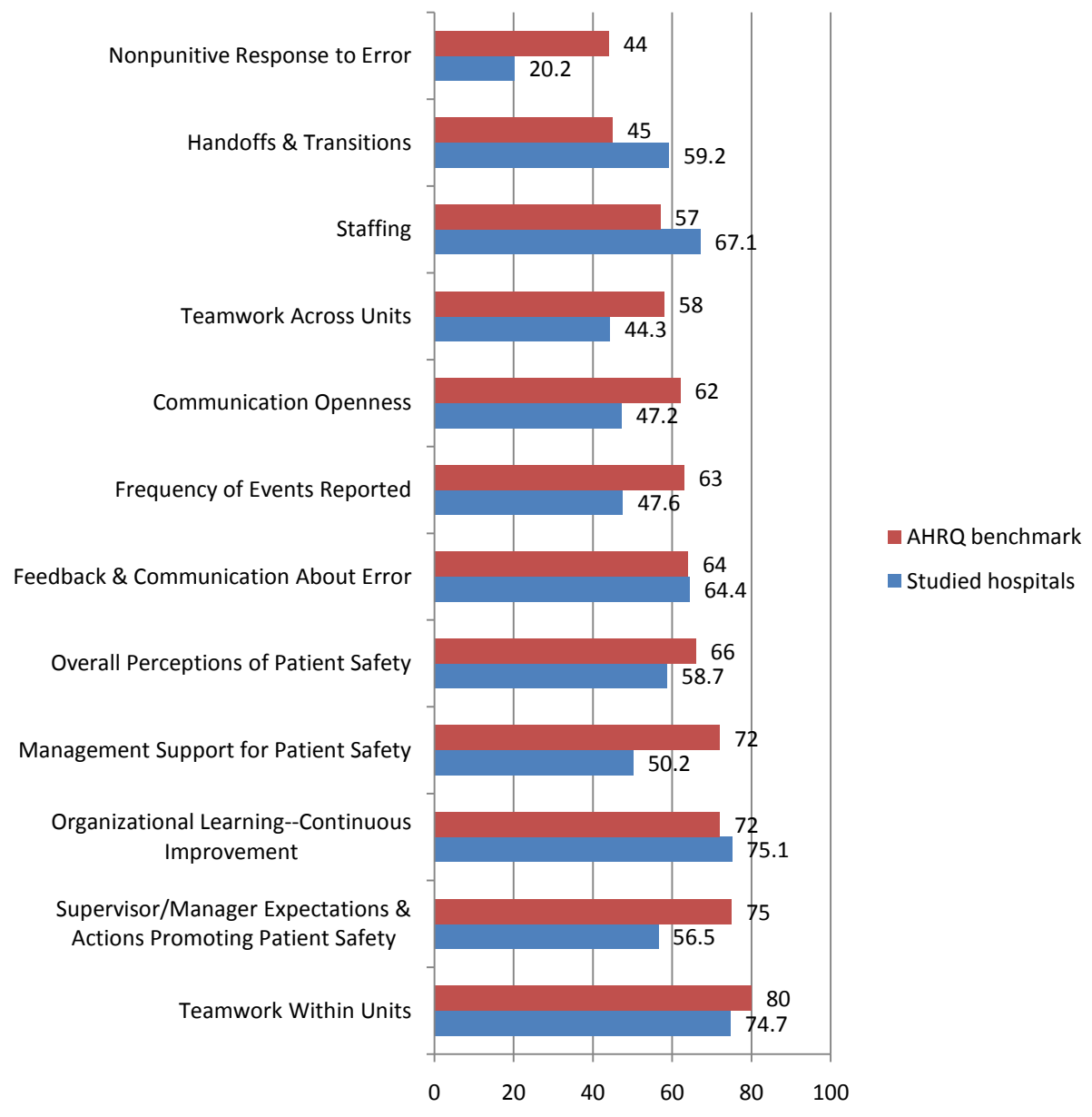

Figure 3. Positive response of participants concerning composites of patient safety culturecomparing studied hospitals and AHRQ benchmark.

in studied hospitals. In Abdi's work the total average percentage of ten dimensions of patient safety culture and two dimensions related its consequences has been 25.9 and 21.9, respectively indicating considerable difference with our study and benchmark report [20]. Furthermore, In Helling's study in Belgium the overall average of 
positive responses has been $48 \%$ [21].

In this study, the most percentage of positive response to dimensions of patient safety culture in studied hospitals is represented by "organizational learning-continuous improvement" and "teamwork within ward", respectively. In line with study findings "teamwork within ward" has had top priority in AHRQ report as well. This aspect of patient safety culture in works of Amiresmaeili [22], Abdi [20], Baghaei [17] has allocated the most positive percentage among participants. In addition, this dimension has been the first priority in FajardoDolci [16] and Bodur [23], studies and second ranking in Mikušová [19]. Teamwork can be used as an effective tool for achieving the goals of any organization. It can also help to prevent any inevitable mistakes happening and changing them to sentinel events and finally harming to both patients and providers [24]. Therefore, organizations can benefit from this opportunity as a way of promoting patient safety programs. Organizational learning has also been the first priority in Fajardo-Dolci [16] and one in Amiresmaeili [22], Baghaei [17] and Bodur [23] and the third priority in benchmark study and Mikušová [19]. Indicating it plays pivotal role in improving patient safety culture. In other words, in order to improve safety culture, healthcare systems should be equipped to information systems supporting learning from experience which could both lead to prevent errors happening promote systems that both prevent errors and reducing their consequences [12].

The lowest positive percentage answer has been to non-punitive response to error in both studies. Our findings are consistent with the results of Abdi [20], Baghaei [17], Bodur [23] and Fajardo-Dolci [16], but the result of this dimension does not correspond with Amiresmaeil [22] and Mikušová [19]. Errors are usually due to defects in the systems and working processes. However, organizations should put aside this thinking that errors and mistakes are results of individuals' failures and consider them as an opportunity for learning.

\section{Conclusions}

In this study, the most participants did not report any error. They evaluated their hospital in an "acceptable" grade. Organizational learning and teamwork within unit were the highest priority of safety culture dimensions and non-punitive response to error was the lowest priority. The findings are to large extent correspondent with AHRQ report. In this regard, the establishment of an effective error reporting system based on "no blame" culture, learning from errors to prevent similar errors and facilitating organizational learning and adopting teamwork strategies to improve performance and enhance patient safety are recommended. Finally, it is recommended to healthcare managers to develop an appropriate action plan to improve dimensions which have great impact on patient safety.

Given the limitations, this study was conducted in only two centers, which is suggested to be done on wider level and at national level preferably to provide the possibility of comprising the centers through setting percentile of each dimension and even each item. In addition, it is suggested that this study will also be conducted at specified intervals to determine what extent each dimension has changed and how the trends of these changes were.

\section{Acknowledgements}

We sincerely grateful all staff, managers and employees of Bushehr selected hospitals that helped us to conduct the study.

\section{References}

[1] El-Jardali, F., Sheikh, F., Garcia, N.A., Jamal, D. and Abdo, A. (2014) Patient Safety Culture in a Large Teaching Hospital in Riyadh: Baseline Assessment, Comparative Analysis and Opportunities for Improvement. BMC Health Services Research, 14, 122. http://dx.doi.org/10.1186/1472-6963-14-122

[2] Wilson, A.M. (2001) Understanding Organisational Culture and the Implications for Corporate Marketing. European Journal of Marketing, 35, 353-367. http://dx.doi.org/10.1108/03090560110382066

[3] Cooper, M.D. (2000) Towards a Model of Safety Culture. Safety Science, 36, 111-136. http://dx.doi.org/10.1016/S0925-7535(00)00035-7

[4] Sorensen, J. (2002) Safety Culture: A Survey of the State-Of-The-Art. Reliability Engineering \& System Safety, 76, 189-204. http://dx.doi.org/10.1016/S0925-7535(00)00035-7

[5] Wamuziri, S. (2006) Safety Culture in the Construction Industry. Proceedings of the Institute of Civil Engineers (ICE)— Municipal Engineer, 159, 167-174. http://dx.doi.org/10.1680/muen.2006.159.3.167 
[6] Colla, J., Bracken, A., Kinney, L. and Weeks, W. (2005) Measuring Patient Safety Climate: A Review of Surveys. Quality and Safety in Health Care, 14, 364-366. http://dx.doi.org/10.1136/qshc.2005.014217

[7] Kohn, L.T., Corrigan, J.M. and Donaldson, M.S. (2000) To Err Is Human: Building a Safer Health System. A Report of the Committee on Quality of Health Care in America, Institute of Medicine, National Academy Press, Washington DC.

[8] Lindberg, L., Judd, K. and Snyder, J. (2008) Developing a Safety Culture with Front-Line Staff. Hospitals \& Health Networks/AHA, 82, 84-85.

[9] Vázquez, J.A.P.C.Y. (2011) Patient Safety: A New Paradigm for a Health System? Cirugía y Cirujanos, 79, $281-282$.

[10] Nieva, V. and Sorra, J. (2003) Safety Culture Assessment: A Tool for Improving Patient Safety in Healthcare Organizations. Quality and Safety in Health Care, 12, ii17-ii23. http://dx.doi.org/10.1136/qhc.12.suppl 2.ii17

[11] Piotrowski, M.M. and Hinshaw, D.B. (2002) The Safety Checklist Program: Creating a Culture of Safety in Intensive Care Units. Joint Commission Journal on Quality and Patient Safety, 28, 306-315.

[12] Driver, T.H., Katz, P.P., Trupin, L. and Wachter, R.M. (2014) Responding to Clinicians Who Fail to Follow Patient Safety Practices: Perceptions of Physicians, Nurses, Trainees, and Patients. Journal of Hospital Medicine, 9, 99-105. http://dx.doi.org/10.1002/jhm.2136

[13] Grote, G. and Künzler, C. (2000) Diagnosis of Safety Culture in Safety Management Audits. Safety Science, 34, 131150. http://dx.doi.org/10.1016/S0925-7535(00)00010-2

[14] Agency for Healthcare Research and Quality (2011) Hospital Survey on Patient Safety Culture. 2011 User Comparative Database Report Contract No. 11-0030.

[15] www.ahrq.gov

[16] Fajardo-Dolci, G., Rodríguez-Suárez, J., Arboleya-Casanova, H., Rojano-Fernández, C., Hernández-Torres, F. and Santacruz-Varela, J. (2011) Patient Safety Culture in Healthcare Professionals. Cirugía y Cirujanos, 78, 522-527.

[17] Baghaei, R., Norani, D., Khalkhali, H.R. and Pirnejad, H. (2011) Assessment of Patient Safety Culture in Health Care Workers of Education Hospitals of Urmia University of Medical Sciences. Journal of Urmia University of Medical Sciences, 10, 155-164. (In Persian)

[18] Thurman, A. (2001) Institutional Responses to Medical Mistakes: Ethical and Legal Perspectives. Kennedy Institute of Ethics Journal, 11, 147-156. http://dx.doi.org/10.1353/ken.2001.0018

[19] Mikušová, V., Rusnáková, V., Nad’ová, K., Boroňová, J. and Bet’ková, M. (2012) Patient Safety Assessment in Slovak Hospitals. International Journal of Collaborative Research on Internal Medicine \& Public Health (IJCRIMPH), 4, 1236-1244.

[20] Abdi, J., Maleki, M.R. and Khosravi, A. (2011) Staff's Preception of Patient Safety Culture in Selected Hospitals of Tehran University of Medical Sciences. Payesh, 10, 19. (In Persian)

[21] Hellings, J., Schrooten, W., Klazinga, N. and Vleugels, A. (2007) Challenging Patient Safety Culture: Survey Results. International Journal of Health Care Quality Assurance, 20, 620-632. http://dx.doi.org/10.1108/09526860710822752

[22] Amiresmaili, M.R., Tourani, S. and Barati, O. (2010) Measuring Safety Culture and Setting Priorities for Action at an Iranian Hospital. Al Ameen Journal of Medical Sciences, 3, 237-245.

[23] Bodur, S. and Filiz, E. (2009) A Survey on Patient Safety Culture in Primary Healthcare Services in Turkey. International Journal for Quality in Health Care, 21, 348-355. http://dx.doi.org/10.1093/intqhc/mzp035

[24] Leonard, M., Graham, S. and Bonacum, D. (2004) The Human Factor: The Critical Importance of Effective Teamwork and Communication in Providing Safe Care. Quality and Safety in Health Care, 13, i85-i90.

http://dx.doi.org/10.1136/qshc.2004.010033 
Scientific Research Publishing (SCIRP) is one of the largest Open Access journal publishers. It is currently publishing more than 200 open access, online, peer-reviewed journals covering a wide range of academic disciplines. SCIRP serves the worldwide academic communities and contributes to the progress and application of science with its publication.

Other selected journals from SCIRP are listed as below. Submit your manuscript to us via either submit@scirp.org or Online Submission Portal.
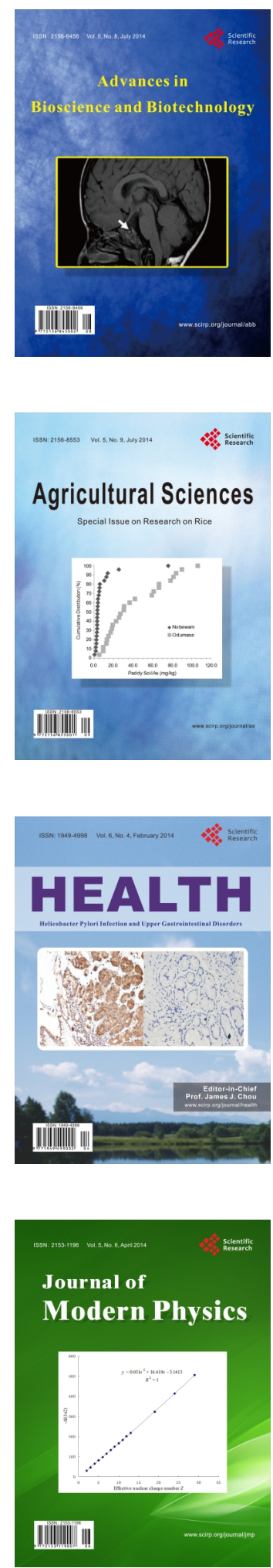
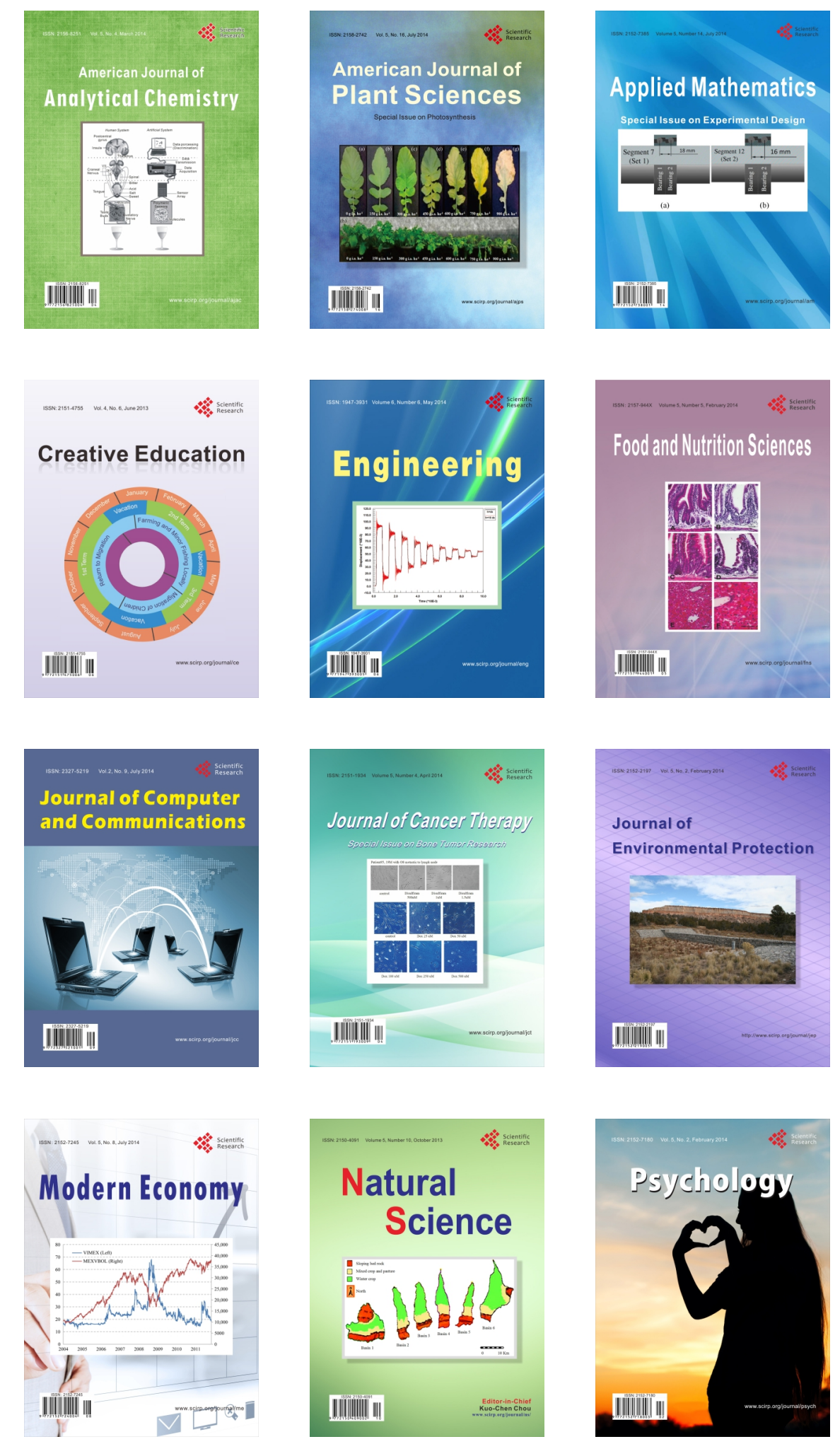